\title{
Differences and similarities between the upper and lower airway: focusing on innate immunity*
}

\author{
Hyung-Ju Cho 1,2,3,\#, Jong Gyun Ha 1,\#, Sang Nam Lee ${ }^{1,2}$, Chang-Hoon Kim,3, \\ De-Yun Wang ${ }^{4,+}$, Joo-Heon Yoon ${ }^{1,2,3,+}$ \\ ' Department of Otorhinolaryngology, Yonsei University College of Medicine, Seoul, Korea \\ ${ }^{2}$ Global Research Laboratory for Allergic Airway Disease, Yonsei University College of Medicine, Seoul, Korea \\ ${ }^{3}$ The Airway Mucus Institute, Yonsei University College of Medicine, Seoul, Korea \\ ${ }^{4}$ Department of Otolaryngology, Yong Loo Lin School of Medicine, National University of Singapore, Singapore
}

Rhinology 59: 0, 0- 0, 2021

https://doi.org/10.4193/Rhin21.046

* Received for publication:

June 21, 2021

Accepted: June 30, 2021

\# These authors contributed equally

† Contributed equally as a correspon-

ding author

\begin{abstract}
The nose is the first respiratory barrier to external pathogens, allergens, pollutants, or cigarette smoke, and vigorous immune responses are triggered when external pathogens come in contact with the nasal epithelium. The mucosal epithelial cells of the nose are essential to the innate immune response against external pathogens and transmit signals that modulate the adaptive immune response. The upper and lower airways share many physiological and immunological features, but there are also numerous differences. It is crucial to understand these differences and their contribution to pathophysiology in order to optimize treatments for inflammatory diseases of the respiratory tract. This review summarizes important differences in the embryological development, histological features, microbiota, immune responses, and cellular subtypes of mucosal epithelial cells of the nose and lungs.
\end{abstract}

Key words: epithelium, innate immunity, lower airway, nose, pathophysiology, upper airway

\section{Introduction}

Upon entering the upper respiratory tract, bacteria, viruses, fungi, allergens, and air pollutants are trapped in the mucous layer of the nasal cavity. Innate immunity is triggered when airway epithelial cells recognize these foreign substances trapped within the nasal mucosa. These responses are fast and non-specific, providing a favorable local tissue microenvironment as a first line defense mechanism. In contrast to the adaptive response of $T$ and $B$ cells, most of the innate immune responses within the epithelium are activated non-specifically by various foreign substances. The reactive epithelial cells consist of basal cells, intermediator progenitor cells (suprabasal cells), goblet cells, and ciliated and non-ciliated columnar cells. Various immune reactions can be elicited in response to pathogen-associated molecular pattern molecules (PAMPs) and damage-associated molecular patterns (DAMPs), including cytokine and chemokine production and release, tight junction damage due to foreign protease activity, and loss of differentiated epithelial cells, such as goblet cells and ciliated cells. In some cases, pathological regeneration of the epithelial cells results in intermediate progenitor cell hyperplasia (formerly basal cell hyperplasia), goblet cell hyperplasia, or squamous metaplasia.

Many studies have been conducted on inflammatory diseases of the lower airway, such as pneumonia, cystic fibrosis, asthma, and chronic obstructive pulmonary disease (COPD). However, comprehensive studies on upper airway inflammatory diseases, such as rhinosinusitis and allergic rhinitis, are lacking because of difficulties in creating mouse models and collecting sufficient numbers of nasal epithelial cells from these mice. Using human nasal mucosal specimens and primary human and mouse nasal epithelial cells, previous studies have identified differences between the upper and lower airway epithelium. This review briefly summarizes the differences in development, microbiota, and histological characteristics of the upper and lower airways, but focuses on the stark differences in the innate immune response and epithelial cell subtypes (Table 1). 


\begin{tabular}{|c|c|c|c|}
\hline & Upper airway & Lower airway & Reference \\
\hline Embryology & $\begin{array}{l}\text { The external nose and nasal cavities develop from } \\
\text { the ectoderm }\end{array}$ & $\begin{array}{l}\text { The lung develops from the anterior foregut } \\
\text { endoderm }\end{array}$ & $(1-6)$ \\
\hline \multirow{3}{*}{ Histology } & Absence of smooth muscle & $\begin{array}{l}\text { Presence of smooth muscle causing bronchocon- } \\
\text { striction }\end{array}$ & $(8,12)$ \\
\hline & Polyps develops causing chronic sinusitis & Polyp does not develop & $(9,10)$ \\
\hline & $\begin{array}{l}\text { Vascular system contains exchange, resistance, and } \\
\text { capacitance vessels }\end{array}$ & $\begin{array}{l}\text { Vascular system lacks resistance and capacitance } \\
\text { vessels }\end{array}$ & $(11,12)$ \\
\hline \multirow[b]{2}{*}{ Microbiome } & $\begin{array}{l}\text { Actinobacteria }>\text { Firmicutes }>>\text { Proteobacteria and } \\
\text { Bacteroidetes } \\
\text { (nasal swab from healthy adults) }\end{array}$ & $\begin{array}{l}\text { Bacteroidetes }>>\text { Proteobacteria, Firmicutes }>>\text { few } \\
\text { Actinobacteria } \\
\text { (BALF from healthy adults) }\end{array}$ & \multirow[b]{2}{*}{$(84)$} \\
\hline & $\begin{array}{l}\text { Firmicutes }(54.7 \%)>> \\
\text { Actinobacteria }(21 \%)> \\
\text { Proteobacteria }(20.4 \%)>>\text { Bacteroidetes }(3.2 \%) \\
\text { (nasopharynx swab from children) }\end{array}$ & $\begin{array}{l}\text { Firmicutes }(48.6 \%)>>\text { Bacteroidetes }(29.5 \%)>> \\
\text { Proteobacteria }(14.8 \%)>\text { Actinobacteria }(2.2 \%) \\
\text { (BALF from children) }\end{array}$ & \\
\hline Mucociliary system & $\begin{array}{l}\text { More submucosal glands per area } \\
\text { More potent and sensitive secretory responses to } \\
\text { secretagogues }\end{array}$ & $\begin{array}{l}\text { Fewer submucosal glands per area } \\
\text { Less potent and sensitive secretory responses to } \\
\text { secretagogues }\end{array}$ & $(29)$ \\
\hline \multirow{5}{*}{ Immunological reaction } & $\begin{array}{l}\text { Rhinovirus infection in HNECs triggers antiviral } \\
\text { activity of RIG-I-dependent interferon }\end{array}$ & $\begin{array}{l}\text { Rhinovirus infection in HBECs robustly activates } \\
\text { NRF2-dependent antioxidant defense }\end{array}$ & $(37)$ \\
\hline & $\begin{array}{l}\text { LPS from } P \text {. aeruginosa causes hypersecretion of IL- } 6 \\
\text { from HNECs of COPD patients }\end{array}$ & $\begin{array}{l}\text { LPS from P. aeruginosa does not cause hypersecre- } \\
\text { tion of IL- } 6 \text { from HBECs of COPD patients }\end{array}$ & $(85)$ \\
\hline & $\begin{array}{l}\text { Cigarette smoke extract does not change TLR4 } \\
\text { expression }\end{array}$ & $\begin{array}{l}\text { Cigarette smoke extract significantly decreases } \\
\text { TLR4 expression }\end{array}$ & $(85)$ \\
\hline & $\begin{array}{l}\text { TLR2 acts as the main PRR when HNECs are ex- } \\
\text { posed to HDM extracts }\end{array}$ & \multirow{2}{*}{$\begin{array}{l}\text { TLR4 acts as the main PRR when HBECs are exposed } \\
\text { to HDM extracts } \\
\text { Lower expression of SARS-CoV-2 virus receptor } \\
\text { (ACE2) and influenza virus receptors (ST6GAL1, } \\
\text { ST6GAL4) }\end{array}$} & $(42)$ \\
\hline & $\begin{array}{l}\text { High expression of SARS-CoV-2 virus receptor } \\
\text { (ACE2) and influenza virus receptors (ST6GAL1, } \\
\text { ST6GAL4) }\end{array}$ & & $(38-41)$ \\
\hline
\end{tabular}

\section{Differences in the upper and lower airway}

\section{Embryological development}

The upper respiratory tract develops in conjunction with the development of the skull. Most structures of the face and neck originate from the pharyngeal arch, which consists of an outer ectodermal layer and an inner epithelial layer of endodermal origin ${ }^{(1)}$. Development of the nose is a highly pre-coordinated programmed event that occurs during embryonic weeks 4-8 and Carnegie stages 13-19 ${ }^{(2)}$. The development of the external nose and nasal cavities begins when nasal placodes arise from ectodermal thickening of the frontonasal process ${ }^{(3,4)}$. These nasal placodes gradually deepen inward to form the nasal pits, which serve as primitive nostrils and nasal cavities. Interestingly, whereas the epithelium of most of the respiratory tract (e.g., pharynx, trachea, bronchus, lungs, etc.) originates from the endoderm, the nasal cavity, the beginning of the respiratory tract, is of ectodermal origin ${ }^{(1,3-6)}$.

\section{Histological features}

The mucosa of the upper and lower airways shares common histological features. Airway mucosa consist of ciliated respiratory epithelium, the lamina propria with submucosal glands, and the basement membrane with type IV and V collagen ${ }^{(7)}$. Inflammation of the respiratory mucosa causes a variety of changes in both the epithelial and lamina propria layers, such as decreases in the number of ciliated epithelial cells and increases in the number of mucin-secreting goblet cells, respectively. Other changes include epithelial shedding, basement membrane thickening, submucosal gland hypertrophy, subepithelial fibrosis, and angiogenesis.

In the lower airway, remodeling during inflammation is characterized by the smooth muscle becoming hypertrophic and causing bronchoconstriction ${ }^{\left({ }^{8}\right)}$. However, the nasal mucosa of the upper airway lacks smooth muscles (except those in blood vessels), and remodeling of the nasal epithelium with allergic inflammation or chronic rhinosinusitis leads to the development of polyps ${ }^{(9,10)}$. These polyps develop when the fibroblasts in the lamina propria overgrow, causing epithelial protrusions and rupture of the basement membrane.

There are also large differences in vascular system of the upper and lower airways. The lamina propria layer of the nasal mucosa contains exchange, resistance, and capacitance vessels ${ }^{(11)}$, but the lower airway lacks both resistance and capacitance vessels. The resistance vessels of the nasal mucosa regulate blood flow in the entire capillary vessel network and constriction of these vessels traps blood in large capacitance vessels, such as the sinusoid, causing congestion of the upper respiratory tract ${ }^{(12)}$. 


\section{Microbiota}

In 2007, the Human Microbiome Project, led by the National Institutes of Health, broadened our understanding of microbiota within the human body ${ }^{(13)}$. Healthy microbiota not only compete with other germs for space, but also prevent infection by releasing compounds that can directly eliminate other bacteria (14). The upper and lower airways differ in the composition and origin of their microbiomes. The nasal microbiome has a more complex polymicrobial community than the throat or sputum (15). In bronchoalveolar lavage fluid (BALF) from the lungs of normal adults, Bacteroidetes and Prevotella were the most dominant, followed by Firmicutes and Proteobacteria. In the nasal cavity, the most common bacteria were Actinobacteria and Firmicutes, with lesser numbers of Proteobacteria and Bacteroidetes. Staphylococcacea was dominant in the nasal cavity, but this type of Firmicutes bacterium was not significantly detected in the oral cavity, BALF, or gastric samples ${ }^{(16)}$. The bacterial composition of healthy lungs was most similar to the oral cavity, suggesting that the lung microbiome is maintained by microbial immigration from the oral cavity rather than from the nasal cavity ${ }^{(16)}$. Although the composition and diversity of the microbiome of the lung and nose are different, the microbial diversity of both tissues decreases with pathogenic conditions, suggesting that the immune response differentially affects the competitiveness of individual microbial species. In a study comparing healthy individuals and patients with chronic lung disease (bronchial asthma and COPD), loss of microbiome heterogeneity was observed in diseased lungs ${ }^{(17,18)}$. Similarly, the diversity of nasal microbiota decreases in other pathogenic conditions, such as chronic rhinosinusitis (CRS) with or without nasal polyp ${ }^{(19,20)}$. However, one study found no difference in microbiome diversity among control, allergic rhinitis, and CRS without nasal polyp patients (21). Instead, allergic rhinitis patients had a higher abundance of Firmicutes, Proteobacteria, Actinobacteria and Bacteroidetes and a lower abundance of Lactobacillus than control group individuals ${ }^{(21)}$. Haemophilus was more abundant in the CRS patients than in the controls or allergic rhinitis patients ${ }^{(21)}$. Nevertheless, research indicates that the composition of the microbiome can trigger the host innate immune response: commensal Staphylococcus isolated from the epidermidis stimulated nasal epithelia to produce antimicrobial peptides killing pathogenic competitors ${ }^{(22)}$. The microbiome of CRS patients may also affect the prognosis of surgical treatment, with greater bacterial diversity associated with better surgical outcomes. In particular, a greater proportion of Actinobacteria correlates with a better prognosis after surgery ${ }^{(23)}$.

Microbiomes can interact with the host to elicit the host immune reaction. In one study, co-culture of nasal epithelial cells with $P$. aeruginosa (PAO1), which is the most common causative agent of CRS, resulted in high levels of IL-17C mRNA and lipocalin-2 that interfered with iron uptake and inhibition of infection
(24). High IgE levels in allergic rhinitis patients has also been associated with dysbiosis of inferior turbinate mucosa, with increased abundance of $S$. aureus and decreased $P$. acnes. This suggests that nasal microbiota may be associated with allergen sensitization and the pathophysiology thereof ${ }^{(25)}$.

As our knowledge of microbiota increases, it will become even more important to further assess the interactions between the microbiota and immune system of the airway epithelium, especially for respiratory diseases such as asthma and allergy ${ }^{(26)}$. It will also be critical to understand how the nasal microbiome changes with airway infection. However, it will be difficult to interpret whether the decreased diversity of the microbiome is a contributing factor in the disease or whether the diversity is merely a response to the inflammation of the disease. There are still limitations to classifying all species within the microbiome, but our understanding will be enhanced through in vivo animal experiments conducted in germ-free facilities. In addition, future studies will need to address the association between the intestinal and nasal microbiomes.

\section{Mucociliary system and ciliary activity}

The rheological properties of airway surface liquid (ASL), which covers the surface of the respiratory mucosa, change in response to various factors, including viral or bacterial infections, allergen exposure, primary mucus abnormalities, and drugs, and these changes affect mucociliary movement. In the respiratory tract, abnormal mucociliary transport results in pulmonary infections, as well as recurrent rhinosinusitis and nasal polyps in the sinonasal cavity ${ }^{(27)}$. ASL consists of an upper gel layer (mucus) and a lower sol layer (periciliary fluid). Most ASL originates from submucosal glands, and stimulation of these glands leads to increased ASL volume, which enhances mucociliary transport (28). There are distinct differences between nasal and trachealbronchial submucosal glands: Nasal glands are more densely distributed throughout the airway than tracheal glands. Also, the secretion rates of nasal glands are about $30 \%$ of those of tracheal glands, despite outnumbering tracheal glands by three times ${ }^{(29)}$. Finally, carbachol and forskolin, which are agonists for gland secretion, are more potent against nasal glands than for tracheal glands ${ }^{(29)}$. These different physiological aspects of secretion between the nasal and tracheal glands can lead to different innate immune responses to various stimuli.

\section{Epithelial barrier integrity}

In airway diseases, disruption of the epithelial barrier is one pathological change upon which the chance of pathogen invasion increases. Respiratory epithelial cells form cell-cell junctions through several structures, including tight junctions, adherence junctions, gap junctions, desmosomes, and hemidesmosomes. These cell-cell junctions not only form extracellular connections between adjacent cells, but also serve as intracellular connec- 


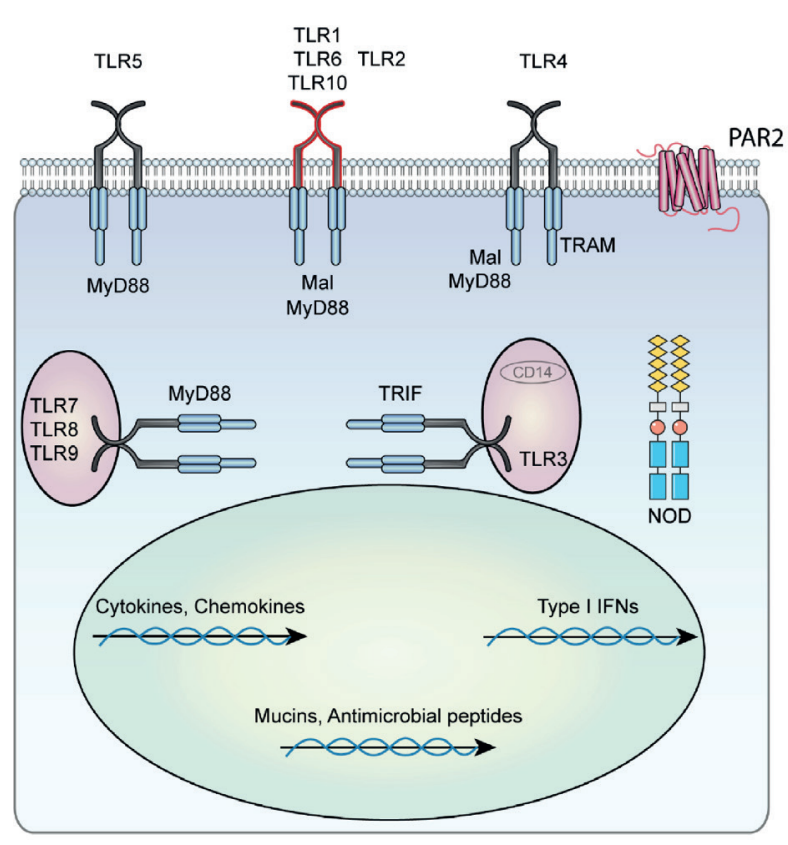

Figure 1. Pattern recognition receptors of the epithelium. Pattern recognition receptors (PRRs) recognize viruses, bacteria, allergens, or air pollutants and initiate innate immune responses. PPRs can be divided into membrane-bound and cytosolic receptors. Toll-like receptors (TLRs) 1, 2, 4, 5, 6, and 10 are membrane-bounded PPRs. TLRs 3, 7, 8, 9, and NOD are cytosolic receptors. Protease-activating receptor (PAR)- 2 is a transmembrane receptor that can be activated by exogenous proteases from various allergens.

tions between different types of cytoskeletons. This junctional structure maintains the homeostasis of the mucosal epithelium by controlling structural integrity, ion diffusion, solute and microbe permeation, and cell proliferation and migration ${ }^{(30)}$. The epithelial barrier can be disrupted under hypoxic conditions. Indeed, various chronic airway inflammatory diseases have been found to be related to mucosal and systemic hypoxia ${ }^{(31)}$. In one study, the expression of VEGF among nasal epithelial cells was found to increase under hypoxic stimulation, resulting in an increase in transepithelial permeability, as reflected in transepithelial electrical resistance. This was rescued by anti-VEGF monoclonal antibody (bevacizumab) and small interfering RNA specific for HIF-1 a (32): HIF-1a plays an essential role in immune and inflammatory responses. VEGF was suppressed by HIF-1a siRNA in OVA-treated murine tracheal epithelial cells, thereby ameliorating airway inflammation and hyperresponsiveness ${ }^{(33)}$. Meanwhile, HIF-1a also plays a protective role in the lower airway epithelium. In oxidative barrier dysfunction, pre-exposure to hypoxia elevating HIF-1a attenuated the loss of transepithelial electrical resistance and increased permeability ${ }^{(34)}$. The barrier function of the airway epithelium has also been found to be impaired in asthma, as indicated by reduced expression of E-cadherin and ZO-1 ${ }^{(35)}$. This damage is similarly observed in allergic rhinitis patients and type 2-driven chronic airway inflammation, which affects both the upper and lower airways ${ }^{(36)}$.

\section{Immune responses to foreign stimuli}

Epithelial cells of the respiratory tract are the first to encounter external foreign stimuli entering the airway. Different immune reactions are elicited in response to bacteria, viruses, allergens, fine dust, or pressure, and these varied responses are dependent on the receptors activated within each tissue or organ. A targeted immune response for each stimulus allows for effective regulation and control of the inflammatory responses. Because the expression of pattern recognition receptors (PRR), the composition of the epithelium, response reactions, and microenvironments of the nose and lungs are different, the mechanisms of innate immunity are also likely to be different.

Several studies have already reported differences in the responsiveness of the nose and lungs to external stimuli ${ }^{(37-44)}$. In rhinovirus infection of respiratory epithelium, innate immunity is triggered by activation of retinoic acid-inducible gene I (RIG-I) - like receptors (RLR). Initiation of the RLR signaling pathway occurs preferentially in nasal epithelial cells rather than in bronchial epithelial cells ${ }^{(37)}$. In terms of susceptibility to rhinovirus, bronchial epithelial cells show 20 40 folds greater rhinovirus replication and release of infectious progeny by greater production of pro-inflammatory cytokines and chemokines ${ }^{(45)}$. The upper and lower airways' response to the SARS-CoV-2 virus, which has been rapidly spreading worldwide in recent years, is an excellent example of how the bio-physiological characteristics of the airways affect the course of infection. While both the upper and lower airway epithelium co-express angiotensin-converting enzyme 2 (ACE2) and transmembrane serine protease 2 (TMPRSS2), which are the entry receptors for SARS-CoV-2 virus ${ }^{(38)}$, these receptors are expressed at higher levels in the ciliated and goblet cells of nasal epithelial cells compared to the lower airway ${ }^{(38-41)}$. As a result, nasal epithelial cells are more susceptible to infection by SARS-CoV-2 and there is a striking gradient of SARS-CoV-2 infection from the nose to the lower airway ${ }^{(40)}$. Similarly, the nasal epithelium expresses higher levels of alanine aminopeptidase (ANPEP), an HCoV-220E receptor, and influenza virus receptors, such as beta-galactoside alpha-2,6-sialyltransferase 1 (ST6GAL1) and beta-galactoside alpha-2,6-sialyltransferase 4 (ST6GAL4) ${ }^{(39)}$. In contrast, the MERS$\mathrm{CoV}$ receptor, dipeptidyl peptidase 4 (DPP4), is highly expressed in the lower airway, especially in alveolar type II cells ${ }^{(39)}$. With respect to allergic inflammation, house dust mites trigger different immune responses in the upper and lower airways. The initial immunological reaction to house dust mite allergens begins with airway epithelial cells. In allergic rhinitis patients, upregulation of toll-like receptors (TLR 2, 3, 4) has been observed ${ }^{(46)}$, and $\beta$-glucan, which is present on house dust mites, plays a 


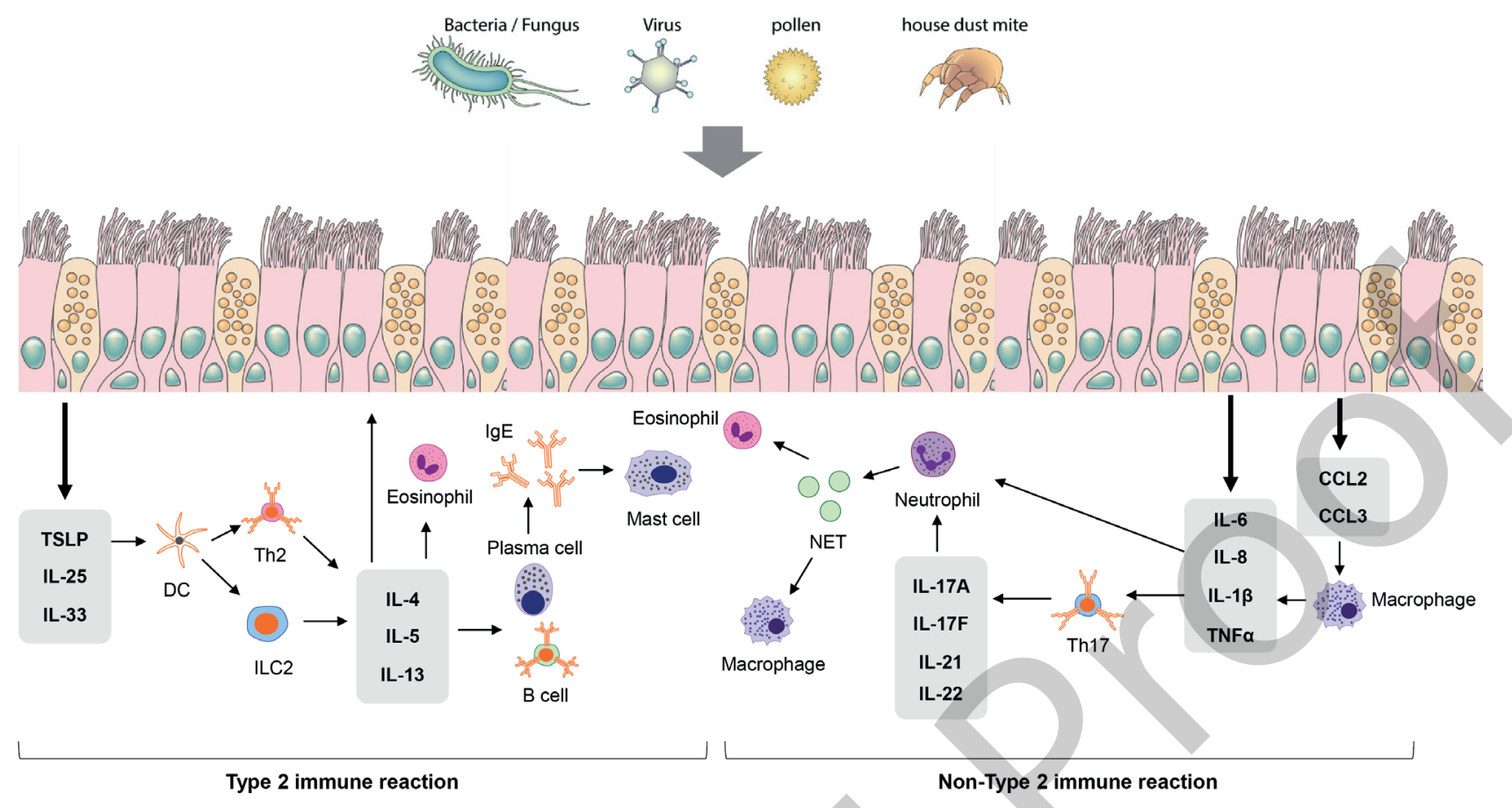

Figure 2. Role of epithelial cells in the pathophysiology underlining type 2 and non-type 2 immune responses. IL-25 IL-33, and TSLP are typically released from epithelial cells when exposed to allergens, leading to production of IL-4, IL-5, and IL-13 via activation of type 2 helper T (Th2) cells and innate lymphoid cells type 2 (ILC2). This type 2 immune response induces recruitment of eosinophils. IL-6, IL-8, IL-1 $\beta$, TNFa, CCL2, and CCL3 are typically released from epithelial cells when exposed to viruses or bacteria, leading to activation of Th17 cells and recruitment of neutrophils.

vital role in TLR2-mediated innate mucosal immunity in the nose ${ }^{(42)}$. Meanwhile, in the lungs, house dust mites induce innate immunity through TLR4. TLR4 is one member of the TLR family that is present on airway epithelial cells, and its importance in allergic asthma has been shown through epidemiological and mechanistic studies ${ }^{(47-49)}$. LPS stimulates IL-1 a secretion through TLR4, which releases GM-CSF and IL-33, resulting in dendritic cell recruitment ${ }^{\left({ }^{50}\right)}$. Thus, TLR4 acts primarily as a PRR in asthma, and TLR2 acts as a PRR in allergic rhinitis ${ }^{(42-44,51)}$ (Figure 1). Further research is still needed to determine how signaling pathways are activated in a tissue-specific manner through specific PAMPs and TLRs.

The epithelium-derived cytokines, such as IL-25, IL-33, and TSLP, are central regulators for type 2 immune responses in the airway epithelium ${ }^{(52)}$ (Figure 2). The expression of these cytokines is elevated in AR, CRS, asthma, and chronic obstructive pulmonary disease and can initiate a type 2 response through conditioning dendritic cells ${ }^{(53)}$. However, the expression levels of these cytokines are not synchronous and parallel because they involve a complex regulatory network ${ }^{(53-55)}$. Further studies of the differential roles of these cytokines in upper and lower airway diseases are still needed.

\section{Epithelial cell subtypes}

Specific diseases and their immunological responses result in altered cellular and molecular phenotypes of single cells in the epithelium ${ }^{(56)}$. Mucus overproduction and goblet cell hyperplasia are often observed in allergic rhinitis, chronic rhinosinusitis, asthma, and chronic obstructive pulmonary disease. To investigate changes in phenotypes, multi-omics analysis of the epigenome, transcriptome, proteome, metabolome, and microbiome can be utilized. These omics approaches provide biological insights through statistical datasets and enable translational research ${ }^{(57)}$. For example, transcriptomics can identify differential gene expression patterns between individuals with and without asthma and allergic diseases ${ }^{(58-60)}$. A few studies have outline glucocorticoid steroid treatment responses using a transcriptomics approach ${ }^{(61)}$. In chronic rhinosinusitis, the comparison of eosinophilic and non-eosinophilic nasal polyps with transcriptomic analysis revealed distinct transcriptome profiles and suggested crucial pathways associated with inflammation, immune responses, and extracellular microenvironment ${ }^{(62)}$. A multi-layered omics approach can provide many useful biomarkers that are useful as measurable indicators of the presence,

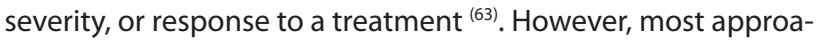
ches analyze cells in bulk, and their results can mask or overlook some essential factors between individual disease-associated cells ${ }^{(64)}$.

Recent advances in single-cell and computational analyses have enabled identification of new classes and characteristics of cells 


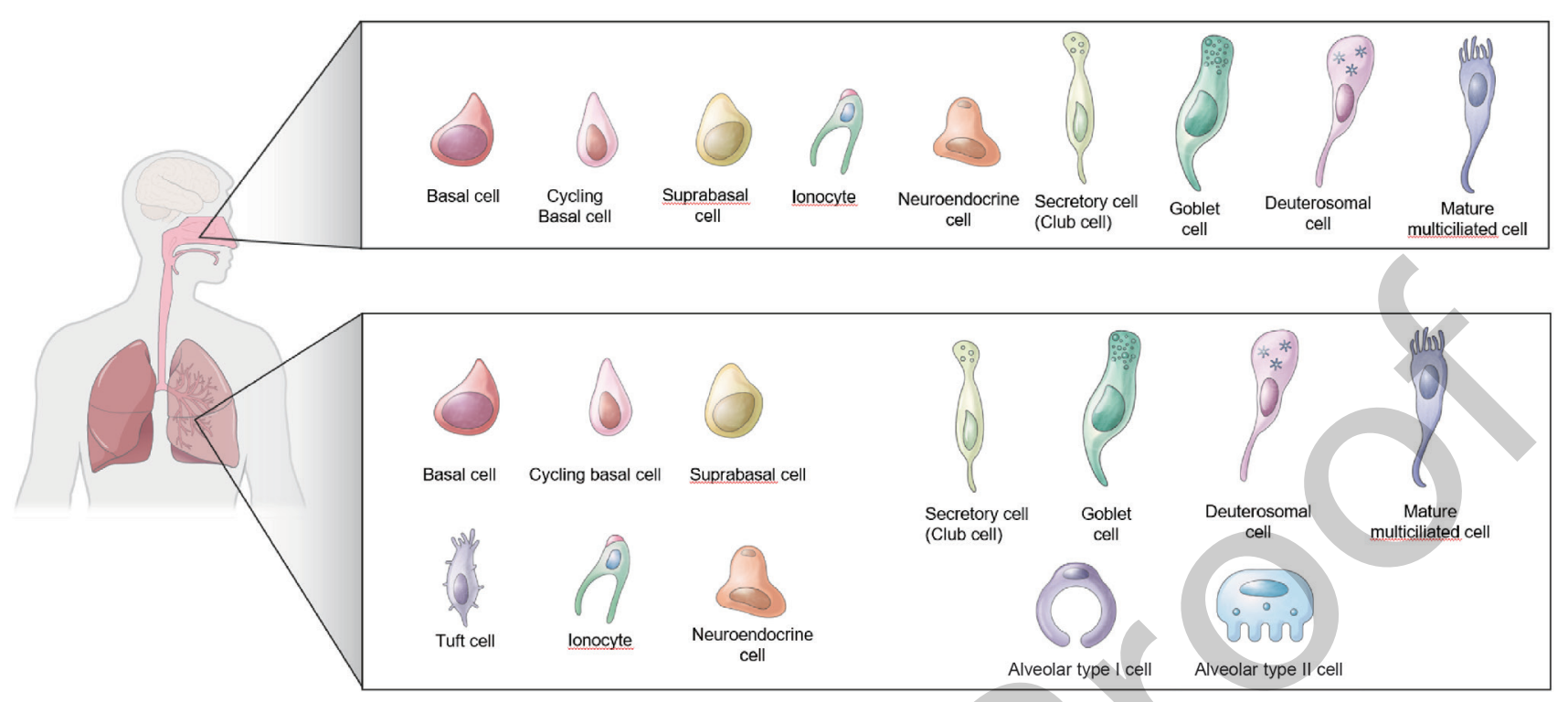

Figure 3. Comparison of upper and lower airway epithelium cell types by single-cell RNA sequencing. Recent single-cell RNAseq studies separated epithelial cells of the upper airway into mature multiciliated cells, deuterosomal cells, goblet cells, secretory (club) cells, neuroendocrine cells, ionocytes, suprabasal cells, cycling basal cells, and non-cycling basal cells $(67,68)$. However, the nomenclature and genetic markers of these cells has not been fully established and may vary across studies. The mucosal epithelium of the upper airway contains some cell types found in the lower airway, but the ionocyte or neuroendocrine cells have not been fully characterized for the upper airway.

based on their genomes ${ }^{(65,66)}$. The Human Cell Atlas consortium recently described relationships in tissues from various organs ${ }^{(66)}$. In particular, research on human lung cells provided valuable knowledge for understanding the pathophysiology of various diseases of the lower airway ${ }^{(65)}$. Because of the numerous differences already discussed in this review, analysis at the individual cell level is likely to identify even more differences in the upper and lower airway epithelium. Therefore, it will be important to classify cell types of the upper respiratory tract through single-cell analysis and to analyze and interpret the genome and function of each cell. To date, there are quite a few single-cell RNA sequencing studies of the epithelium.

Using single-cell RNA sequencing (RNAseq), Garcia et al. clustered human and animal nasal mucosal epithelial cells into six subtypes: cycling basal, non-cycling basal, suprabasal, club, goblet, deuterosomal and multiciliated ${ }^{(67)}$ (Figure 3). Interestingly, this in-depth analysis divided the FOXJ1-positive cells into two large clusters, mature multiciliated cells and deuterosomal cells. Mature multiciliated cells are characterized by the expression of DNAH5, whereas deuterosomal cells express proteins related to the synthesis of basal bodies in motile cilia. Using various markers, the researchers successfully predicted the developmental trajectories of basal cells into luminal cells. In the first single-cell RNA assay on nasal polyps, Ordovas-Montanes et al. determined that basal progenitor cells in nasal polyps retain intrinsic memory for IL-4 and IL-13 stimulation ${ }^{(68)}$. Blocking IL-4 receptors in vivo corrected this problem associated with basal and secretory cells.

In the lower airway, bronchial mucosal epithelial cells can be classified as ciliated, pre-ciliated, goblet, secretory (also known as "club cells"), cycling basal, basal, and ionocytes ${ }^{(69-71)}$. The chemosensory intestinal tuft cell, or brush cell, is a rare cell type thought to be involved in nerve stimulation and transmission because it synapses with the cholinergic nerve, but its function is not yet clear ${ }^{(72,73)}$. Ionocytes, which are also rare, express FOXI1, CFTR, and multiple subunits of the vacuolar-type $\mathrm{H}+$ -ATPase (V-ATPase). The amount of periciliary fluid is controlled by active ion transport through epithelial cells at the cellular level. One of the primary ion channels that release $\mathrm{Cl}$ - along with the secretion of water from the surface of respiratory epithelial cells is CFTR. In experiments using single-cell RNAseq, we determined that the nasal epithelium also has subtypes of ionocytes expressing FOXI1 and CFTR (unpublished data). CFTR was mainly expressed in ionocytes in the lower airway, but CFTR was also expressed in FOXI1-negative cells in the upper airway. Our analyses suggest that genes expressed within each epithelial cell subtype can differ between the nose and lungs. Recently, Scudieri P et al. reported that the nasal epithelium has a relatively high ( $3 \%)$ amount of ionocytes, whereas ionocytes are very rare in the bronchi ${ }^{(74)}$, suggesting the existence of a proximal-distal gradient with a progressively decreasing number of ionocytes. Therefore, the role of ionocytes in the upper and lower airway epithelium needs further characterization. Epithelial cell-derived cytokines, including thymic stromal lymp- 


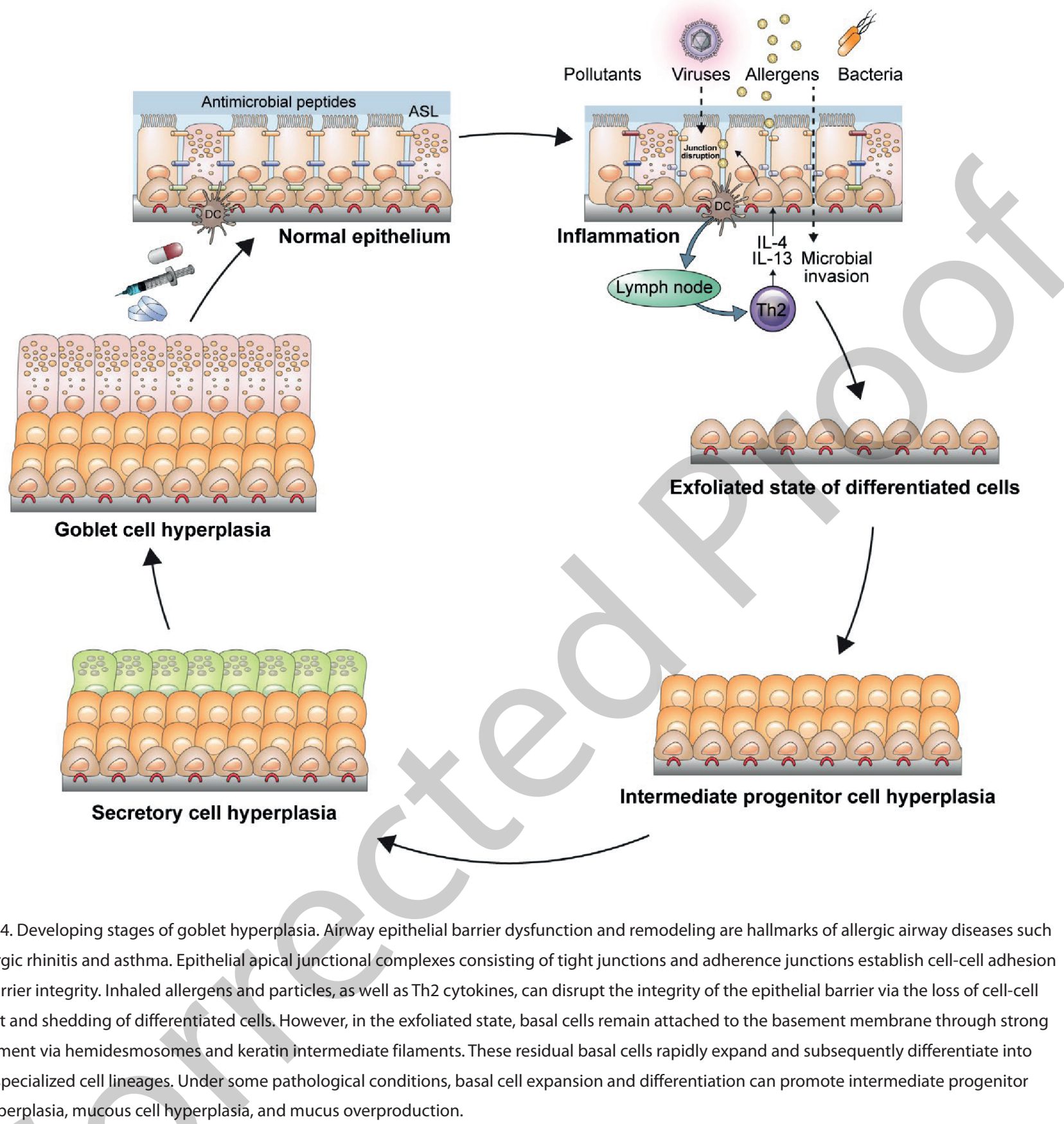

hopoietin (TSLP), IL-33, and IL-25, can exacerbate allergic airway diseases by augmenting the type 2 immune responses to allergens, pathogens, and other environmental particles ${ }^{(75)}$ (Figure 2). These cytokines activate and induce cytokine production from a broad range of cell populations, including dendritic cells, type 2 innate lymphoid cells, mast cells, memory Th2 cells, sensory neurons, eosinophils, and basophils ${ }^{(75-77)}$. These cytokines are up-regulated in asthma, allergic rhinitis, and CRS with nasal polyps (CRSwNP) with high eosinophilia ${ }^{(54,78-80)}$. A recent singlecell RNAseq study in CRSWNP showed that distinct subsets of basal epithelial cells express TSLP and IL-33 ${ }^{(68)}$. These cytokines contribute to type 2 inflammation through the recruitment and activation of effector cells in the nasal mucosa and influence airway remodeling through effects on basal cell expansion and differentiation into specialized cells ${ }^{(68)}$.

Epithelium-derived IL-25 can promote to the infiltration of eosinophils into nasal polyps. This cytokine is primarily expressed by solitary chemosensory cells (SCCs) and the progenitor cell population that can terminally differentiate into SCCs ${ }^{(81)}$. SCCs are a specialized cell type in the nasal epithelium that expresses taste receptors and chemosensory signaling proteins. These cells are present in increased numbers in nasal polyp tissues ${ }^{(81)}$. 
Interestingly, a recent study demonstrated that non-eosinophilic nasal polyps express significantly higher levels of IL-33 compared to eosinophilic nasal polyps, suggesting that non-eosinophilic nasal polyps are involved in neutrophil recruitment and remodeling ${ }^{(82)}$.

Basal cells and intermediate progenitor cells are the most important cells governing differentiation and regeneration following epithelial cell injury (Figure 4). Basal cells are firmly attached to the basement membrane through hemidesmosomes and cytokeratins; this makes them relatively resistant to external stimuli. In contrast, terminally differentiated ciliated cells have weak tight junctions, are more easily damaged by external stimuli, and have difficulty regenerating themselves ${ }^{\left({ }^{(3)}\right)}$. When the ciliated cells die or are shed in response to injury, basal cells proliferate and differentiate to replenish the number of intermediate progenitor cells, which further differentiate into ciliated cells, goblet cells, or squamous cells. Pathological expansion of basal or intermediate cells can lead to intermediate progenitor cell hyperplasia, goblet cell hyperplasia, and squamous metaplasia (Figure 4).

Future single-cell RNAseq analyses will need to separate basal cells from intermediate progenitor cells. However, all the currently identified intermediate progenitor cells markers are intracellular proteins and cannot be used for single-cell RNAseq because this method requires live cells. Furthermore, collection methods can skew the subtype of nasal mucosal epithelial cells in the sample. Basal cells cannot be efficiently isolated from samples collected by brushing the nasal mucosa, but sufficient numbers of basal cells can be obtained from the excised inferior turbinate. Additional limitations include the cost and time constraints of acquiring large samples of rare cells and individualspecific differences within healthy or disease groups. Despite these limitations, distinguishing and analyzing gene expression at the single-cell level can be used to identify new diseaseassociated cell types and to investigate the cellular hierarchy during epithelial cell differentiation. In addition, transcript analyses of cells can provide a detailed understanding of how gene transcripts are altered in pathological states. Other cell surface receptors that recognize external stimuli, such as PRRs or EGFR, can also be used to identify certain cell types and monitor changes during pathological states.

\section{Conclusion}

The upper and lower respiratory tracts have different embryological, histological, microbial, immunological, and genetic characteristics. Therefore, it is important to focus separately on the upper and the lower airways when studying respiratory diseases mechanisms. Future studies combining single-cell RNAseq and single-cell proteomics will more accurately identify new epithelial cell types and their functions, trajectories, and immunoreactivities. Furthermore, by selectively turning on/off genes in specific cellular subtypes, future treatments may be able to minimize or reverse the development of airway epithelium-related diseases.

\section{Acknowledgements}

This work was supported by grants from the Global Research Laboratory Program of the National Research Foundation of Korea (NRF) funded by the Ministry of Science, Information and Communications Technology (ICT), and Future Planning grant 2016K1A1A2910779 (J.-H.Y.).

The authors thank Medical Illustration \& Design, a part of the Medical Research Support Services of Yonsei University College of Medicine, for their artistic support related to this work.

\section{Authorship contribution}

Study concept and design: JHY, DYW; Writing: HJC, JGH, JHY; Reference analysis and manuscript review: SNL, CHK.

\section{Conflict of interest}

No conflict of interests.

\section{References}

. Pohunek P. Development, structure and function of the upper airways. Paediatr Respir Rev 2004; 5(1):2-8.

2. Kim CH, Park HW, Kim K, Yoon JH. Early development of the nose in human embryos: a stereomicroscopic and histologic analysis. Laryngoscope 2004; 114(10):1791-1800

3. Steding $\mathrm{G}$. The development of the nose. The Anatomy of the Human Embryo : A Scanning Electron-Microscopic Atlas. Basel: Karger, 2008; 146-165.

4. Hooper JE, Feng W, Li H, et al. Systems biology of facial development: contributions of ectoderm and mesenchyme. Dev Biol 2017; 426(1):97-114.

5. Swarr DT, Morrisey EE. Lung endoderm morphogenesis: gasping for form and function. Annu Rev Cell Dev Biol 2015; 31:553573.

6. Kadzik RS, Morrisey EE. Directing lung endoderm differentiation in pluripotent stem cells. Cell Stem Cell 2012; 10(4):355-361.

7. Paulsson M. Basement membrane proteins: structure, assembly, and cellular interactions. Crit Rev Biochem Mol Biol 1992; 27(12):93-127.

8. Samitas K, Carter A, Kariyawasam HH, Xanthou G. Upper and lower airway remodelling mechanisms in asthma, allergic rhinitis and chronic rhinosinusitis: The one airway concept revisited. Allergy 2018; 73(5):993-1002

9. Meng J, Zhou P, Liu Y, et al. The develop- ment of nasal polyp disease involves early nasal mucosal inflammation and remodelling. PLoS One 2013; 8(12):e82373.

10. Hellquist HB. Nasal polyps update. Histopathology. Allergy Asthma Proc 1996; 17(5):237-242.

11. Widdicombe J. Microvascular anatomy of the nose. Allergy 1997; 52(40 Suppl):7-11.

12. Gizurarson S. Anatomical and histological factors affecting intranasal drug and vaccine delivery. Curr Drug Deliv 2012; 9(6):566-582.

13. Turnbaugh PJ, Ley RE, Hamady M, FraserLiggett CM, Knight R, Gordon Jl. The human microbiome project. Nature 2007; 449(7164):804-810.

14. Zhang N, Van Crombruggen K, Gevaert 
E, Bachert C. Barrier function of the nasa mucosa in health and type-2 biased airway diseases. Allergy 2016; 71(3):295-307.

15. Boutin S, Graeber SY, Weitnauer M, et al. Comparison of microbiomes from different niches of upper and lower airways in children and adolescents with cystic fibrosis. PLoS One 2015; 10(1):e0116029.

16. Bassis CM, Erb-Downward JR, Dickson RP, et al. Analysis of the upper respiratory tract microbiotas as the source of the lung and gastric microbiotas in healthy individuals. MBio 2015; 6(2):e00037

17. Monsó E. Microbiome in chronic obstructive pulmonary disease. Ann Transl Med 2017; 5(12):251.

18. Sze MA, Dimitriu PA, Hayashi S, et al. The lung tissue microbiome in chronic obstructive pulmonary disease. Am J Respir Crit Care Med 2012; 185(10):1073-1080.

19. Choi EB, Hong SW, Kim DK, et al. Decreased diversity of nasal microbiota and their secreted extracellular vesicles in patients with chronic rhinosinusitis based on a metagenomic analysis. Allergy 2014; 69(4):517-526.

20. Lal D, Keim P, Delisle J, et al. Mapping and comparing bacterial microbiota in the sinonasal cavity of healthy, allergic rhinitis, and chronic rhinosinusitis subjects. Int Forum Allergy Rhinol 2017; 7(6):561-569.

21. Gan W, Yang F, Meng J, Liu F, Liu S, Xian J. Comparing the nasal bacterial microbiome diversity of allergic rhinitis, chronic rhinosinusitis and control subjects. Eur Arch Otorhinolaryngol 2021; 278(3):711-718.

22. Liu Q, Liu Q, Meng H, et al. Staphylococcus epidermidis Contributes to Healthy Maturation of the Nasal Microbiome by Stimulating Antimicrobial Peptide Production. Cell Host Microbe 2020; 27(1):68-78 e65.

23. Ramakrishnan VR, Hauser LJ, Feazel LM, Ir D Robertson CE, Frank DN. Sinus microbiota varies among chronic rhinosinusitis phenotypes and predicts surgical outcome. Allergy Clin Immunol 2015; 136(2):334-342. e331.

24. Jeon YJ, Jo A, Won J, et al. Interleukin-17C protects nasal epithelium from pseudomonas aeruginosa infection. Am J Respir Cell Mol Biol 2019. doi:10.1165/rcmb.20180377OC.

25. Hyun DW, Min HJ, Kim MS, et al. Dysbiosis of Inferior Turbinate Microbiota Is Associated with High Total IgE Levels in Patients with Allergic Rhinitis. Infect Immun 2018; 86(4).

26. Dickson RP, Erb-Downward JR, Huffnagle $\mathrm{GB}$. The role of the bacterial microbiome in lung disease. Expert Rev Respir Med 2013; 7(3):245-257.

27. Jang $Y$ J, Lee $\mathrm{CH}$. Localization of cystic fibrosis transmembrane conductance regulator in epithelial cells of nasal polyps and postoperative polypoid mucosae. Acta Otolaryngol 2001; 121(1):93-97.

28. Knowles MR, Boucher RC. Mucus clearance as a primary innate defense mechanism for mammalian airways. J Clin Invest 2002; 109(5):571-577.

29. Cho HJ, Joo NS, Wine JJ. Defective fluid secretion from submucosal glands of nasal turbinates from CFTR-/- and CFTR (DeltaF508/DeltaF508) pigs. PLoS One 2011; 6(8):e24424

30. Garcia MA, Nelson WJ, Chavez N. Cell-Cell Junctions Organize Structural and Signaling Networks. Cold Spring Harb Perspect Biol 2018; 10(4)

31. Page LK, Staples KJ, Spalluto CM, Watson A, Wilkinson TMA. Influence of Hypoxia on the Epithelial-Pathogen Interactions in the Lung: Implications for Respiratory Disease. Front Immunol 2021; 12:653969.

32. Song HA, Kim YS, Cho HJ, et al. Hypoxia Modulates Epithelial Permeability via Regulation of Vascular Endothelial Growth Factor in Airway Epithelia. Am J Respir Cell Mol Biol 2017; 57(5):527-535.

33. Kim SR, Lee KS, Park HS, et al. HIF-1alpha inhibition ameliorates an allergic airway dis ease via VEGF suppression in bronchial epithelium. Eur J Immunol 2010; 40(10):28582869.

34. Olson N, Hristova M, Heintz NH, Lounsbury KM, van der Vliet A. Activation of hypoxiainducible factor-1 protects airway epithelium against oxidant-induced barrier dysfunction. Am J Physiol Lung Cell Mol Physiol 2011; 301(6):L993-L1002.

35. Holgate ST. The sentinel role of the airway epithelium in asthma pathogenesis. Immunol Rev 2011;242(1):205-219.

36. Hellings PW, Steelant B. Epithelial barriers in allergy and asthma. J Allergy Clin Immunol 2020; 145(6):1499-1509.

37. Mihaylova VT, Kong Y, Fedorova O, et al. Regional Differences in Airway Epithelial Cells Reveal Tradeoff between Defense against Oxidative Stress and Defense against Rhinovirus. Cell Rep 2018 ; 24(1.1):3000-3007.e3003.

38. Ziegler CGK, Allon SJ, Nyquist SK, et al. SARS-CoV-2 Receptor ACE2 Is an InterferonStimulated Gene in Human Airway Epithelial Cells and Is Detected in Specific Cell Subsets across Tissues. Cell 2020; 181(5):1016-1035 e1019.

39. Sungnak W, Huang N, Becavin C, et al. SARS$\mathrm{CoV}-2$ entry factors are highly expressed in nasal epithelial cells together with innate immune genes. Nat Med 2020; 26(5):681687

40. Hou YJ, Okuda K, Edwards CE, et al. SARSCoV-2 Reverse Genetics Reveals a Variable Infection Gradient in the Respiratory Tract. Cell 2020; 182(2):429-446 e414.

41. Mick E, Kamm J, Pisco AO, et al. Upper airway gene expression differentiates COVID19 from other acute respiratory illnesses and reveals suppression of innate immune responses by SARS-CoV-2. medRxiv 2020. doi:10.1101/2020.05.18.20105171.

42. Ryu JH, Yoo JY, Kim MJ, et al. Distinct TLRmediated pathways regulate house dust mite-induced allergic disease in the upper and lower airways. J Allergy Clin Immunol 2013; 131(2):549-561.

43. Phipps S, Lam CE, Kaiko GE, et al. Toll/IL-1 signaling is critical for house dust mitespecific helper T cell type 2 and type 17 [corrected] responses. Am J Respir Crit Care Med 2009; 179(10):883-893.

44. Hammad H, Chieppa M, Perros F, Willart MA Germain RN, Lambrecht BN. House dust mite allergen induces asthma via Toll-like receptor 4 triggering of airway structural cells. Nat Med 2009; 15(4):410-416.

45. Lopez-Souza N, Favoreto S, Wong $\mathrm{H}$, et al. In vitro susceptibility to rhinovirus infection is greater for bronchial than for nasal airway epithelial cells in human subjects. J Allergy Clin Immunol 2009; 123(6):13841390 e 1382.

46. Fransson $M$, Adner $M$, Erjefalt J, Jansson L, Uddman R, Cardell LO. Up-regulation of Tolllike receptors 2, 3 and 4 in allergic rhinitis. Respir Res 2005; 6:100.

47. Braun-Fahrlander C, Riedler J, Herz U, et al. Environmental exposure to endotoxin and its relation to asthma in school-age children. N Engl J Med 2002; 347(12):869-877.

48. Gereda JE, Leung DY, Thatayatikom A, et al. Relation between house-dust endotoxin exposure, type $1 \mathrm{~T}$-cell development, and allergen sensitisation in infants at high risk of asthma. Lancet 2000; 355(9216):16801683.

49. Eisenbarth SC, Piggott DA, Huleatt JW, Visintin I, Herrick CA, Bottomly K. Lipopolysaccharide-enhanced, toll-like receptor 4-dependent T helper cell type 2 responses to inhaled antigen. J Exp Med 2002; 196(12):1645-1651

50. Willart MA, Deswarte $K$, Pouliot $P$, et al Interleukin-1alpha controls allergic sensitization to inhaled house dust mite via the epithelial release of GM-CSF and IL-33. J Exp Med 2012; 209(8):1505-1517.

51. Trompette A, Divanovic S, Visintin A, et al Allergenicity resulting from functional mimicry of a Toll-like receptor complex protein. Nature 2009; 457(7229):585-588.

52. Patel NN, Kohanski MA, Maina IW, Workman AD, Herbert DR, Cohen NA. Sentinels at the wall: epithelial-derived cytokines serve as triggers of upper airway type 2 inflammation. Int Forum Allergy Rhinol 2019; 9(1):9399.

53. Hong $H$, Liao $S$, Chen $F$, Yang $Q$, Wang DY. Role of IL-25, IL-33, and TSLP in triggering united airway diseases toward type 2 inflammation. Allergy 2020; 75(11):27942804.

54. Liao B, Cao PP, Zeng M, et al. Interaction of thymic stromal lymphopoietin, IL-33, and their receptors in epithelial cells in eosinophilic chronic rhinosinusitis with nasal polyps. Allergy 2015; 70(9):1169-1180

55. Xu G, Zhang L, Wang DY, et al. Opposing roles of $\mathrm{IL}-17 \mathrm{~A}$ and $\mathrm{IL}-25$ in the regulation of TSLP production in human nasal epithelial cells. Allergy 2010; 65(5):581-589.

56. Tata PR, Rajagopal J. Plasticity in the 
lung: making and breaking cell identity. Development 2017; 144(5):755-766.

57. Hasin $Y$, Seldin M, Lusis A. Multi-omics approaches to disease. Genome Biol 2017; 18(1):83.

58. Ivanova O, Richards LB, Vijverberg SJ, et al. What did we learn from multiple omics studies in asthma? Allergy 2019; 74(11):2129-2145.

59. Donovan BM, Bastarache L, Turi KN, Zutter MM, Hartert TV. The current state of omics technologies in the clinical management of asthma and allergic diseases. Ann Allergy Asthma Immunol 2019: 123(6):550-557.

60. Kan M, Shumyatcher M, Himes BE. Using omics approaches to understand pulmonary diseases. Respir Res 2017; 18(1):149.

61. Ortiz RA, Barnes KC. Genetics of allergic diseases. Immunol Allergy Clin North Am 2015; 35(1):19-44.

62. Wang W, Gao Z, Wang $H$, et al. Transcriptome Analysis Reveals Distinct Gene Expression Profiles in Eosinophilic and Noneosinophilic Chronic Rhinosinusitis with Nasal Polyps. Sci Rep 2016; 6:26604.

63. Breiteneder H, Peng YQ, Agache I, et al. Biomarkers for diagnosis and prediction of therapy responses in allergic diseases and asthma. Allergy 2020; 75(12):3039-3068.

64. Shalek AK, Benson M. Single-cell analyses to tailor treatments. Sci Transl Med 2017; 9(408).

65. Schiller HB, Montoro DT, Simon LM, et al. The Human Lung Cell Atlas: A HighResolution Reference Map of the Human Lung in Health and Disease. Am J Respir Cell Mol Biol 2019; 61(1):31-41.

66. Regev A, Teichmann SA, Lander ES, et al. The Human Cell Atlas. Elife 2017; 6.

67. Ruiz Garcia S, Deprez M, Lebrigand K, et al. Novel dynamics of human mucociliary differentiation revealed by single-cell RNA sequencing of nasal epithelial cultures. Development 2019; 146(20).

68. Ordovas-Montanes J, Dwyer DF, Nyquist $S K$, et al. Allergic inflammatory memory in human respiratory epithelial progenitor cells. Nature 2018; 560(7720):649-654.

69. Gras D, Chanez P, Vachier I, Petit A, Bourdin
A. Bronchial epithelium as a target for innovative treatments in asthma. Pharmacol Ther 2013; 140(3):290-305.

70. Kotton DN, Morrisey EE. Lung regeneration: mechanisms, applications and emerging stem cell populations. Nat Med 2014; 20(8):822-832.

71. Plasschaert LW, Zilionis R, Choo-Wing R, et al. A single-cell atlas of the airway epithelium reveals the CFTR-rich pulmonary ionocyte. Nature 2018; 560(7718):377-381.

72. Krasteva G, Canning BJ, Hartmann $P$, et al. Cholinergic chemosensory cells in the trachea regulate breathing. Proc Natl Acad Sc U S A 2011; 108(23):9478-9483.

73. Montoro DT, Haber AL, Biton M, et al. A revised airway epithelial hierarchy includes CFTR-expressing ionocytes. Nature 2018; 560(7718):319-324.

74. Scudieri P, Musante I, Venturini A, et al. lonocytes and CFTR Chloride Channel Expression in Normal and Cystic Fibrosis Nasal and Bronchial Epithelial Cells. Cells 2020; 9(9).

75. Roan F, Obata-Ninomiya K, Ziegler SF. Epithelial cell-derived cytokines: more than just signaling the alarm. J Clin Invest 2019; 129(4):1441-1451.

76. Corren J, Ziegler SF. TSLP: from allergy to cancer. Nat Immunol 2019; 20(12):16031609.

77. Chan BCL, Lam CWK, Tam LS, Wong CK IL33: Roles in Allergic Inflammation and Therapeutic Perspectives. Front Immunol 2019; 10:364

78. Hunninghake GM, Soto-Quiros ME, Avila $L$, et al. TSLP polymorphisms are associated with asthma in a sex-specific fashion. Allergy 2010; 65(12):1566-1575.

79. Bunyavanich S, Melen E, Wilk JB, et al. Thymic stromal lymphopoietin (TSLP) is associated with allergic rhinitis in children with asthma. Clin Mol Allergy 201 1; 9:1.

80. Corrigan CJ, Wang W, Meng Q, et al. Allergen-induced expression of $\mathrm{IL}-25$ and IL-25 receptor in atopic asthmatic airways and late-phase cutaneous responses. J Allergy Clin Immunol 2011; 128(1):116-124.

81. Kohanski MA, Workman AD, Patel NN, et al.
Solitary chemosensory cells are a primary epithelial source of IL-25 in patients with chronic rhinosinusitis with nasal polyps. J Allergy Clin Immunol 2018; 142(2):460-469 e467.

82. Kim DK, Jin HR, Eun KM, et al. The role of interleukin-33 in chronic rhinosinusitis. Thorax 2017; 72(7):635-645.

83. Rawlins EL, Ostrowski LE, Randell SH, Hogan BL. Lung development and repair: contribution of the ciliated lineage. Proc Natl Acad Sci U S A 2007; 104(2):410-417.

84. Kloepfer KM, Deschamp AR, Ross SE, et al. In children, the microbiota of the nasopharynx and bronchoalveolar lavage fluid are both similar and different. Pediatr Pulmonol 2018. 53(4):475-482.

85. Comer DM, Elborn JS, Ennis M. Comparison of nasal and bronchial epithelial cells obtained from patients with COPD. PLoS One 2012; 7(3):e32924.

Joo-Heon Yoon, MD, PhD

Department of Otorhinolaryngology Yonsei University College of Medicine 50-1 Yonsei-ro, Seodaemun-gu,

Seoul, Korea, 03722

Office: 82-2-2228-3610

Email:jhyoon@yuhs.ac

Fax: 82-2-393-0580

De-Yun Wang, MD, PhD

Department of Otolaryngology Yong Loo Lin School of Medicine, National University of Singapore $1 E$ Kent Ridge Road, Singapore 119228, Singapore

Email: entwdy@nus.edu.sg 